\title{
Restless Legs Syndrome Caused by Quetiapine
}

\author{
Young-Min Park \\ Department of Psychiatry, Ilsan Paik Hospital, Inje University College of Medicine, Goyang, Korea
}

In addition to patients presenting with primary restless legs syndrome (RLS), clinicians may also encounter patients presenting with drug-induced RLS. Drug-induced RLS is a commonly observed adverse event in patients receiving atypical antipsychotics (AAP). The individual AAPs have been shown to induce RLS at varying frequencies. In particular, olanzapine and quetiapine have been reported to induce RLS at higher rate than do the other AAPs. Considering quetiapine's low affinity for the dopamine receptor, AAP-induced RLS cannot be attributed to the degree of dopamine blockade alone. Observations from previous pharmacokinetic studies indicating that quetiapine exhibits transiently high D2 occupancy when initially administered could offer an explanation for this high rate of RLS induction. Several additional reports have indicated that the symptoms of RLS may be exacerbated by administration of anti-histaminic drugs, which is of interest in the context of quetiapine's high affinity for the $\mathrm{H} 1$ receptor. Still, the exact mechanism by which AAPs induce RLS remains unclear. This article will review the current clinical evidence regarding quetiapine-induced RLS.

Key Words: Quetiapine; Restless legs syndrome; Atypical antipsychotics

Received: December 10, 2019 Revised: February 6, 2020 Accepted: February 6, 2020

Corresponding author: Young-Min Park, MD, PhD, Department of Psychiatry, Ilsan Paik Hospital, Inje University College of Medicine, 170 Juhwa-ro, Ilsanseo-gu, Goyang 10380, Korea.

Tel: 82-31-910-7260, Fax: 82-31-910-7268, E-mail: medipark@hanmail.net

(a) This is an Open Access article distributed under the terms of the Creative Commons Attribution Non-Commercial License (https://creativecommons.org/licenses/bync/4.0) which permits unrestricted non-commercial use, distribution, and reproduction in any medium, provided the original work is properly cited.

\section{INTRODUCTION}

While in clinical practice, clinicians may encounter patients presenting with drug-induced restless legs syndrome (RLS) in addition to those presenting with primary RLS. RLS is particularly and commonly observed in patients receiving atypical antipsychotics (AAP), which as a class are known to exert their clinical effect through antagonism of the dopamine receptor. However, the probability at which administration of the individual AAPs may induce RLS has been seen to be inconsistent. Quetiapine and olanzapine in particular have been observed to be potent inducers of RLS. As such, it is difficult to ascribe AAP-induced RLS to dopamine antagonism alone when considering quetiapine's low affinity for the dopamine receptor.

\section{PATHOPHYSIOLOGY OF QUETIAPINE- INDUCED RLS}

RLS has previously been associated with iron deficiency, pregnancy, kidney disease, and rheumatoid disease as well as disruption of dopamine and histamine signaling [1]. Additionally, asso- ciations between drug-induced RLS and dopamine (D2) receptor blockers, histamine receptor blockers, antidepressants, lithium, and caffeine have been described [2].

\section{Dopamine and quetiapine-induced RLS}

The mechanism by which AAPs may induce RLS remains unclear. The primary mechanism has been suspected to be related to a disruption in dopaminergic signaling [3]. However, by this reasoning, quetiapine would be expected to induce RLS at a lower rate than that of olanzapine and risperidone owing to its lesser occupancy of the D2 receptor [3]. This supposition is further questioned by additional observations that quetiapine only loosely binds to the D2 receptor and readily dissociates from it [4]. To that end, other studies have even shown that quetiapine induces akathisia at a similar rate to placebo $[5,6]$. Investigators have hypothesized that quetiapine's tendency to transiently bind D2 at high occupancy [7] when initially administered could be a contributing factor to the high rate of RLS reported during its use [8]. However evidence in support of this mechanism remains inconclusive. 
Histamine and quetiapine-induced RLS

Quetiapine has been found to display a high affinity for the $\mathrm{H} 1$ receptor, and several reports have described exacerbation of RLS symptoms on administration of antihistaminic medication [9]. In addition, some investigators have reported that administration of antihistamines, antidepressants, antipsychotics, and antiemetics may increase the risk of RLS in patients with end stage renal disease [10]. However, at the same time, a recent study has revealed the possible involvement of a striatal histamine mechanism in the pathogenesis of iron-deficiency anemia-induced RLS, and that histamine H3R antagonism may be efficacious in its management [11]. Therefore further study of the relationship between histamine and RLS continues to be warranted.

Iron deficiency and quetiapine-induced RLS

Other studies have suggested involvement of iron dysregulation in the pathogenesis of quetiapine-induced RLS [9]. Iron deficiency has been shown to be a common cause of secondary RLS. Insufficient supply leads to a disruption in dopamine synthesis, increasing variation in the diurnal cycle [9]. An underlying iron deficiency may increase susceptibility to RLS, and supplementation could possibly mitigate symptom severity [12]. Thus, clinicians may benefit from remaining cognizant of a patient's iron status when management has been complicated by the presence of RLS.

\section{DIFFERENCE BETWEEN ANTIPSYCHOTIC- INDUCED AKATHISIA AND ANTIPSY- CHOTIC-INDUCED RLS}

Because severe cases of antipsychotic-induced RLS that have lost circadian variation may be challenging to distinguish from those of akathisia, discerning between the two is sometimes difficult [13]. The symptoms of antipsychotic-induced RLS increase during the night and the discomfort is localized to the lower extremities $[1,14]$. However, patients may describe either condition as an inner restlessness. Given this, RLS should be considered with a higher index of suspicion than akathisia in patients managed on quetiapine, as quetiapine is much more likely to induce the former rather than the latter $[3,4]$.

\section{CASE SERIES OF QUETIAPINE-INDUCED RLS}

A literature search was conducted using the term 'quetiapine' OR 'restless legs syndrome', OR 'RLS' in Medline, EMBASE, and PsycINFO. Table 1 summarizes the results of that search limited to case reports of quetiapine-induced RLS [8,15-24]. Dosages of quetiapine administered in the studies ranged from $25 \mathrm{mg}$ to 600 $\mathrm{mg}$. Low as well as high dosages of quetiapine were seen to be capable of inducing RLS.

Table 1. Summary of case reports on restless legs syndrome caused by quetiapine

\begin{tabular}{|c|c|c|c|c|}
\hline Reference & Onset age (yr)/sex & Dosage (mg) & Diagnosis & Concomitant psychotropics \\
\hline Fountoulakis et al. [15] & $28 / \mathrm{F}$ & 200 & $\mathrm{BD}$ & $\mathrm{Li}$ \\
\hline \multirow[t]{2}{*}{ Catalano et al. [16] } & $43 / \mathrm{F}$ & 50 & MDD & VFX, BZD \\
\hline & $27 / F$ & 25 & MDD & None \\
\hline Pinninti et al. [17] & $68 / \mathrm{F}$ & 200 & BID & None \\
\hline \multirow[t]{2}{*}{ Urbano and Ware [18] } & $53 / \mathrm{F}$ & 600 & BIID & BZD, BUP, OCZ \\
\hline & $52 / \mathrm{F}$ & 600 & BID & BZD, OCZ \\
\hline Chou et al. [19] & $47 / \mathrm{M}$ & 200 & BID & VPA \\
\hline Webb [20] & $44 / \mathrm{M}$ & 600 & BID & None \\
\hline \multirow[t]{7}{*}{ Rittmannsberger and Werl [8] } & $65 / \mathrm{M}$ & 250 & MDD & VFX \\
\hline & $41 / \mathrm{F}$ & 25 & BIID & OCZ, TZD \\
\hline & $54 / \mathrm{F}$ & 100 & MDD & AMT, BZD \\
\hline & $66 / \mathrm{F}$ & 50 & MDD & DXT, MZP \\
\hline & $33 / \mathrm{F}$ & 75 & $\mathrm{BPD}$ & VPA, DXT, OCZ \\
\hline & $49 / \mathrm{F}$ & 200 & MDD & ESC, MZP \\
\hline & $61 / \mathrm{M}$ & 150 & MDD & VFX, BZD \\
\hline Michopoulos et al. [21] & $47 / \mathrm{F}$ & 150 & BIID & VFX \\
\hline \multirow[t]{4}{*}{ Vohra [22] } & $40 / \mathrm{F}$ & N/A & SAD & AMT \\
\hline & $43 / \mathrm{F}$ & 300 & $\mathrm{BD}$ & CTP \\
\hline & $39 / F$ & 250 & MDD & FLX \\
\hline & $38 / \mathrm{F}$ & 300 & MDD & STR \\
\hline Chen [23] & $46 / \mathrm{M}$ & 150 & BIID & ESC, Li \\
\hline Soyata et al. [24] & $39 / \mathrm{F}$ & 100 & MDD & None \\
\hline
\end{tabular}

F: female, M: male, BID: bipolar I disorder, BIID: bipolar II disorder, MDD: major depressive disorder, BPD: borderline personality disorder, SAD: schizoaffective disorder, BD: bipolar disorder, Li: lithium, VFX: venlafaxine, BZD: benzodiazepine, BUP: bupropion, OCZ: oxacarbamazepine, VPA: valproate, TZD: trazodone, AMT: amitryptiline, DXT: duloxetine, MZP: mirtazapine, ESC: escitalopram, CTP: citalopram, FLX: fluoxetine, STR: sertraline 


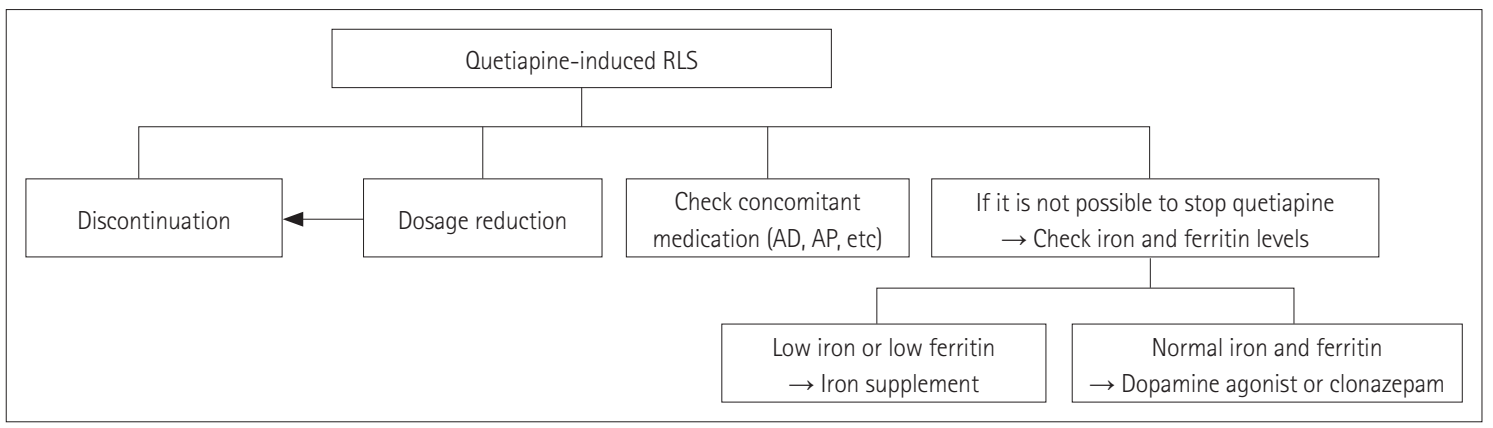

Figure 1. Treatment of quetiapine-induced RLS based on case reports. RLS: restless legs syndrome, AD: antidepressant, AP: antipsychotics.

A total of 22 cases of quetiapine-induced RLS have been reported. Among them, 17 patients were females, and 5 patients were males. These results were consistent with previous studies that reported a higher prevalence of primary RLS in women compared to men [25]. However, the small sample size limits the statistical power of this observation.

Mean age of all patients was 46.5 years. Mean ages of the males and females were 52.6 years and 44.7 years, respectively. A majority of the patients carried psychiatric diagnoses (bipolar disorder, $\mathrm{n}=10$; major depressive disorder, $\mathrm{n}=10$; schizoaffective disorder, $\mathrm{n}=1$; borderline personality disorder, $\mathrm{n}=1$ ). Investigators have hypothesized that depression and RLS could synergistically increase susceptibility to RLS [26]. And although strong evidence is lacking, the effects of concomitant administration of other medications such as antidepressants cannot be discounted. A proposed mechanism for this phenomenon involves inhibition of dopaminergic signaling by selective serotonin reuptake inhibitors [26] Fourteen patients were being managed on a combination of quetiapine and an antidepressant (Table 1). Thus, the effects of antidepressant administration as well as quetiapine administration alone, and that of a possible interaction between an antidepressant and quetiapine on the incidence of RLS could not be individually assessed in those patients. However, in four of the other patients it was possible that quetiapine alone was responsible for the onset of RLS. In one of those patients, a single low dose $(100 \mathrm{mg})$ of quetiapine is believed to have induced RLS. However, at the same time, there has been another report submitted to the literature that documents the mitigation of clonazepam-refractory RLS in a female patient after a single dose of low-dose (25-50 mg) quetiapine [27]. Thus, continued investigation of this matter is required.

The patients were on a wide variety of medications (venlafaxine, $n=4$; amitryptiline, $n=2$; mirtazapine, $n=2$; duloxetine, $n=2$; escitalopram, $n=2$; citalopram, $n=1$; fluoxetine, $n=1$; trazodone, $\mathrm{n}=1$; sertraline, $\mathrm{n}=1$; bupropion, $\mathrm{n}=1$ ). Four patients were on oxcarbamazepine and two patients were on valproate.

\section{TREATMENT OF QUETIAPINE-INDUCED RLS}

Quetiapine-induced RLS is often readily identified, and symptoms usually improve on termination of quetiapine or a dosage re- duction (Figure 1) [8,22]. In times when taking the patient off of quetiapine may be disadvantageous, the addition of a dopamine agonist such as ropinirole or pramipexole, and possibly clonazepam, may serve to mitigate RLS symptoms (Figure 1) $[8,18,22]$. In specific cases, determining serum iron and ferritin levels may be of benefit, as if there were to be a concurrent iron deficiency in a patient with quetiapine-induced RLS, iron supplementation may mitigate symptoms like other secondary RLS. Although there has been no report on iron supplement in a patient with quetiapine-induced RLS, some investigators reported the improvement in antipsychotic-induced akathisia with iron supplement in a patient with iron deficiency [28].

\section{CONCLUSIONS}

Quetiapine-induced RLS is more commonly encountered than that caused by other AAPs [8]. Although the primary pathophysiology has yet to be clearly identified, clinicians should be aware of this adverse effect of quetiapine. Further studies on this matter are necessary.

\section{Acknowledgments}

None

\section{Conflicts of Interest}

The author has no potential conflicts of interest to disclose.

\section{ORCID iD}

Young-Min Park (1)

https://orcid.org/0000-0002-4993-1426

\section{REFERENCES}

1. Ekbom K, Ulfberg J. Restless legs syndrome. J Intern Med 2009;266:419-431.

2. Satija P, Ondo WG. Restless legs syndrome: pathophysiology, diagnosis and treatment. CNS Drugs 2008;22:497-518.

3. Aggarwal S, Dodd S, Berk M. Restless leg syndrome associated with atypical antipsychotics: current status, pathophysiology, and clinical implications. Curr Drug Saf 2015;10:98-105.

4. Goldstein JM. Quetiapine fumarate (Seroquel): a new atypical antipsychotic. Drugs Today (Barc) 1999;35:193-210.

5. Kumar R, Sachdev PS. Akathisia and second-generation antipsychotic drugs. Curr Opin Psychiatry 2009;22:293-299.

6. Kane JM, Fleischhacker WW, Hansen L, Perlis R, Pikalov A 3rd, Assunção- 
Talbott S. Akathisia: an updated review focusing on second-generation antipsychotics. J Clin Psychiatry 2009;70:627-643.

7. Kapur S, Zipursky R, Jones C, Shammi CS, Remington G, Seeman P. A positron emission tomography study of quetiapine in schizophrenia: a preliminary finding of an antipsychotic effect with only transiently high dopamine D2 receptor occupancy. Arch Gen Psychiatry 2000;57:553-559.

8. Rittmannsberger $\mathrm{H}$, Werl R. Restless legs syndrome induced by quetiapine: report of seven cases and review of the literature. Int J Neuropsychopharmacol 2013;16:1427-1431.

9. Ondo WG. Restless legs syndrome. Curr Neurol Neurosci Rep 2005;5:266274.

10. Bliwise DL, Zhang RH, Kutner NG. Medications associated with restless legs syndrome: a case-control study in the US Renal Data System (USRDS). Sleep Med 2014;15:1241-1245.

11. Lai YY, Hsieh KC, Cheng YH, Chew KT, Nguyen D, Ramanathan L, et al. Striatal histamine mechanism in the pathogenesis of restless legs syndrome. Sleep 2019 Oct 31 [Epub]. Available at: https://doi.org/10.1093/sleep/ zsz223.

12. Patatanian E, Claborn MK. Drug-induced restless legs syndrome. Ann Pharmacother 2018;52:662-672.

13. Kang SG, Lee HJ, Jung SW, Cho SN, Han C, Kim YK, et al. Characteristics and clinical correlates of restless legs syndrome in schizophrenia. Prog Neuropsychopharmacol Biol Psychiatry 2007;31:1078-1083.

14. Ferini-Strambi L. RLS-like symptoms: differential diagnosis by history and clinical assessment. Sleep Med 2007;8 Suppl 2:S3-S6.

15. Fountoulakis KN, Iacovides A, Kaprinis SG, Kaprinis GS. Diffuse muscle pain with quetiapine. Br J Psychiatry 2003;182:81.

16. Catalano G, Grace JW, Catalano MC, Morales MJ, Cruse LM. Acute akathisia associated with quetiapine use. Psychosomatics 2005;46:291-301.

17. Pinninti NR, Mago R, Townsend J, Doghramji K. Periodic restless legs syn- drome associated with quetiapine use: a case report. J Clin Psychopharmacol 2005;25:617-618.

18. Urbano MR, Ware JC. Restless legs syndrome caused by quetiapine successfully treated with ropinirole in 2 patients with bipolar disorder. J Clin Psychopharmacol 2008;28:704-705.

19. Chou KJ, Chen PY, Huang MC. Restless legs syndrome following the combined use of quetiapine and paroxetine. Prog Neuropsychopharmacol Biol Psychiatry 2010;34:1139-1140.

20. Webb J. Co-occurring akathisia and restless legs syndrome likely induced by quetiapine. J Neuropsychiatry Clin Neurosci 2012;24:E46-E47.

21. Michopoulos I, Ferentinos P, Oulis P, Gournellis R. Restless legs syndrome associated with the combined use of quetiapine and venlafaxine. J Clin Psychopharmacol 2014;34:159-161.

22. Vohra A. Quetiapine induced restless legs syndrome: a series of four cases. Asian J Psychiatr 2015;16:73-74.

23. Chen PH. Restless leg syndrome induced by escitalopram and lithium combined with quetiapine treatment in bipolar II disorder: a case report. Clin Neuropharmacol 2016;39:118-119.

24. Soyata AZ, Celebi F, Yargc LI. Restless legs syndrome after single low dose quetiapine administration. Curr Drug Saf 2016;11:172-173.

25. Garcia-Borreguero D, Egatz R, Winkelmann J, Berger K. Epidemiology of restless legs syndrome: the current status. Sleep Med Rev 2006;10:153-167.

26. Picchietti D, Winkelman JW. Restless legs syndrome, periodic limb movements in sleep, and depression. Sleep 2005;28:891-898.

27. Boku S, Hirota M, Yoshida H, Homma H, Iwasaki S, Matsubara S. A case of restless legs syndrome successfully treated with quetiapine. Sleep Biol Rhythms 2006;4:193-195.

28. Cotter PE, O'Keeffe ST. Improvement in neuroleptic-induced akathisia with intravenous iron treatment in a patient with iron deficiency. J Neurol Neurosurg Psychiatry 2007;78:548. 